\title{
Adjuvant chemotherapeutic treatment of 1650 patients with early breast cancer in routine care in Germany: data from the prospective TMK cohort study
}

\author{
Steffen Dörfel ${ }^{1}$ - Claus-Christoph Steffens ${ }^{2} \cdot$ Dirk Meyer $^{3} \cdot$ Hans Tesch $^{4} \cdot$ Lisa Kruggel $^{5} \cdot$ Melanie Frank $^{6}$. \\ Martina Jänicke ${ }^{5}$. Norbert Marschner ${ }^{7}$ (1) The TMK-Group (Tumour Registry Breast Cancer)
}

Received: 27 June 2017 / Accepted: 24 November 2017 / Published online: 4 December 2017

(c) The Author(s) 2017. This article is an open access publication

\begin{abstract}
Background Several regimens for which efficacy was established in randomized controlled trials are recommended in current treatment guidelines for early breast cancer. However, knowledge on use and effectiveness of commonly administered chemotherapeutic agents in real-life care and across all breast cancer subtypes is limited.

Methods The prospective, multicentre German TMK cohort study (Tumour Registry Breast Cancer) recruited patients in 148 oncology outpatient-centres. Data from 1650 patients who completed adjuvant chemotherapy were analysed regarding treatment regimens and taxane use from 2007 to 2014. The association of patient characteristics with application of taxanefree regimens was examined with a multivariate regression model.

Results The preferred adjuvant treatment shifted from fluorouracil, anthracycline and cyclophosphamide containing regimens to anthracycline/taxane combinations. Taxane use increased for all subtypes, and the greatest rise was among node-negative patients. Older age, node-negativity, lower grading, HR-positive/HER2-negative subtype and earlier start year of therapy were significantly associated with taxane-free therapy.

Conclusions Treatment with anthracycline/taxane-based chemotherapy in Germany has been rising for every subtype. The increased taxane use reflects updated guideline recommendations over the past decade. Cohort studies like the TMK provide insight into real-life treatment of patients outside of clinical trials.
\end{abstract}

Keywords Breast neoplasms $\cdot$ Registries $\cdot$ Cohort studies $\cdot$ Taxoids $\cdot$ Chemotherapy $\cdot$ Adjuvant

\section{Introduction}

Breast cancer (ICD-10 C.50), with an annual incidence of 70,000 new cases, is the most common type of cancer among women in Germany, and the second most frequent cause of cancer-related death in women [1]. Implementation of screening procedures and development of new therapies revealed constant mortality rates despite increasing incidence; age-standardised mortality declined slightly and the 5 -year relative survival increased over the past decade $[2,3]$.

Electronic supplementary material The online version of this article (https://doi.org/10.1007/s12282-017-0823-7) contains supplementary material, which is available to authorized users.

Norbert Marschner

norbert.marschner@onkologie-freiburg.de

Extended author information available on the last page of the article
Standard therapy of patients with early breast cancer consists of surgery, radiation and adjuvant systemic therapy. However, as breast cancer is highly heterogeneous, the selection of adjuvant systemic therapy depends on stage, histology and on molecular subtypes of the tumour $[4,5]$. Current adjuvant systemic therapy options include chemotherapy, endocrine therapy for hormone receptor (HR)-positive tumours, and targeted biological agents such as trastuzumab for human epidermal growth factor receptor (HER2)-positive tumours. The treatment decision is based on multiple factors and includes-in addition to tumour biology and the predicted sensitivity to particular treatment types-the patients' physical constitution, biological age and comorbidities as well as patients' preferences.

The current St. Gallen international experts consensus recommends endocrine therapy alone for adjuvant systemic therapy of luminal A-like breast cancer subtypes with low risk in the majority of cases, while additional chemotherapy 
should be considered in patients with four or more lymph nodes involved [6]. For luminal B-like HER2-negative subtypes, endocrine therapy and chemotherapy is recommended in the majority of cases, while for luminal B-like HER2-positive subtypes, chemotherapy, anti-HER 2 targeted therapy and endocrine therapy are recommended for all patients. For the triple-negative subtype [oestrogen-receptor (ER)negative, progesterone receptor (PR)-negative and HER2negative], chemotherapy should include an anthracycline and a taxane [6].

Despite these recommendations and other clinical practice guidelines, the extent to which these recommendations are incorporated into routine clinical practice is only partially known [7-9] and often limited by retrospective data collection [10].

There are several regimens for which treatment efficacy has been established in randomized controlled trials (RCTs) [11]. These regimens differ in duration, the combination and the dosages of drugs given. Research in clinical trials usually focuses on treatment with one regimen or drug of interest and also applies stringent selection criteria. As more treatment options have become available, a wider variety of treatments was applied to individual patients in everyday routine care. However, knowledge on the use of existing chemotherapeutic agents and combinations in routine care is limited. Clinical cohort studies like ours can help to fill this gap and provide insight into treatment and outcome of patients in routine care [12].

Today, most systemic breast cancer treatments can be delivered on an outpatient basis. In Germany, ambulatory care is predominantly provided by office-based specialists and hospital outpatient centres. This paper focuses on the cytotoxic treatment of patients with early breast cancer in daily routine practice as well as changes in treatment over time from 2007 to 2014.

\section{Patients and methods}

\section{Data source}

The Tumour Registry Breast Cancer (TMK) is an ongoing, open, prospective, longitudinal, observational, multicentre study for patients with breast cancer. The TMK was established by office-based medical oncologists. The study was approved by the responsible ethics committee and is registered at ClinicalTrial.gov (NCT01351584). Recruitment started in February 2007. 2250 patients with curative treatment intention were enrolled until April 2014, and 2250 patients with palliative treatment intention have been recruited until May 2016. 148 outpatient centres and clinics for medical oncology located all over Germany are actively participating in the TMK. 122 such sites enrolled patients with adjuvant treatment intention. The sites were encouraged to enrol patients consecutively to ensure unselected recruitment. Eligible patients are women aged $\geq 18$ years with histologically confirmed breast cancer and systemic antineoplastic treatment. Written informed consent was obtained from all patients. A maximum of 6 weeks time difference was allowed between start of systemic therapy and signed informed consent. The TMK has previously been described in detail [12].

At enrolment, data on all previous cancer treatments, patients' socio-demographics and tumour characteristics (tumour location, histology, stage, grading, ER-, PR- and HER2-receptor status) are documented. Comorbidity is assessed using the updated Charlson Comorbidity Index (CCI) [13]. Patients are treated according to physicians' choice and visits are scheduled according to their individual treatment regimen. No specifications are imposed on the physicians' assessment for treatment at any time. All patients are followed for up to 5 years from enrolment or until death, loss to follow-up or withdrawal of consent. During the follow-up period, data on all systemic antineoplastic treatments, radiotherapies and surgeries, diagnostic followup controls as well as on outcome and course of the disease are collected. Systemic therapies are documented by listing all agents separately and not as predefined regimens to allow for documentation of individual combinations. Patient data are transferred from medical records to a secure webbased electronic case report form (eCRF) by designated site staff and are updated after each follow-up examination, any change in therapy or at least every 6 months. For quality assurance, automated data plausibility checks are performed and queries are generated by the eCRF software. Manual checks on data completeness and plausibility as well as spot site monitoring are performed regularly to ensure reliability.

\section{Cohort definition}

Data cut-off for the present analysis was October 2014. By then, 4251 patients had been recruited into the TMK. Of these, 1907 patients were recruited at start of systemic adjuvant treatment. The present analysis is based on 1650 patients who completed adjuvant chemotherapy. Details of the patient flow are presented in Fig. 1.

\section{Statistical analysis}

The combinations of documented chemotherapeutic agents were coded into chemotherapy regimen. Anthracyclinebased chemotherapy was defined as receiving epirubicin or doxorubicin (A) alone or in combination with any other antineoplastic drug except paclitaxel or docetaxel. Taxanebased chemotherapy was defined as the use of paclitaxel (P) or docetaxel (D) alone or in combination with any other 


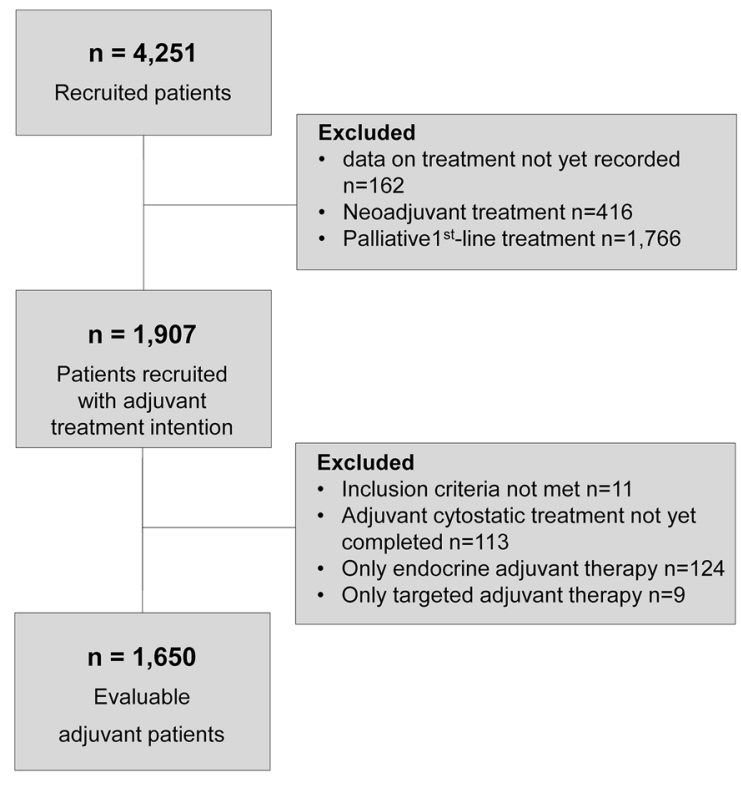

Fig. 1 Cohort definition. Number of patients enrolled in the TMK until October 2014

antineoplastic drug except epirubicin or doxorubicin. Combination therapy with anthracycline and taxane was defined as receiving epirubicin or doxorubicin and paclitaxel or docetaxel, with or without any other additional antineoplastic drug. HR-status was assessed as combination of ER- and/or PR-positive (HR-positive) or both receptors negative (HRnegative). Descriptive analyses were performed using SPSS v.20.0 (IBM Corp.).

Multivariate logistic regression analysis was used to examine the association of patient and tumour characteristics and treatment with taxane-containing chemotherapy (yes/no) as dependent variable. Potential baseline variables for the multivariate regression model were as follows: age at start of therapy (in 10 years increments), CCI, the institution deciding on adjuvant therapy, tumour size, nodal status, grading, molecular subtype and year of treatment start. Based on a stepwise backward selection of variables, using the likelihood ratio test for model comparison, CCI and the institution deciding on adjuvant therapy were not included in the final model. Analysis was performed using $\mathrm{R}$ version 2.15.1. The results were displayed as odds ratios (OR) with $95 \%$ confidence intervals $(95 \% \mathrm{CI})$ and $p$ values. The significance level was set at 0.05 .

\section{Results}

\section{Patient and tumour characteristics}

Table 1 presents demographic and clinical characteristics of patients with early breast cancer at the start of adjuvant chemotherapy. Characteristics are shown for the entire cohort and for patients treated with one of the four most frequent regimens (received by at least $10 \%$ of patients). A table listing the characteristics for all regimens is available in the supplemental material (Table S1). Median age at start of therapy was 56.7 years, $13 \%$ of the patients were aged $\geq 70$. HR- and HER2-status were documented for $98 \%$ ( $n=1611)$ of the patients. More than half $(59 \%)$ of the patients had HR-positive/HER2-negative tumours, 25\% HER2-positive tumours and $16 \%$ triple negative tumours. $47 \%$ of patients were node-negative. $26 \%$ of the patients were pre-menopausal and $58 \%$ were post-menopausal. $53 \%$ of the patients had at least one comorbidity, with hypertension $(28 \%)$ and diabetes ( $8 \%$ ) recorded most frequently. $24 \%$ of the patients were obese (BMI > 30). The majority of patients underwent breast conserving surgery (BCS 71\%), $26 \%$ underwent mastectomy. $86 \%$ of the patients with BCS received radiotherapy post-surgery, in contrast to $60 \%$ of the patients who underwent mastectomy. For more details, see supplemental Table S1.

\section{Chemotherapy regimen}

Figure $2 \mathrm{a}$ shows the most frequently administered chemotherapy regimens over time for all patients. Most regimens were based on the combination of fluorouracil $(\mathrm{F})$, epirubicin or doxorubicin (A) and cyclophosphamide (C). F+ A + C was given to $27 \%$ of the patients $(n=456), \mathrm{F}+\mathrm{A}+\mathrm{C}$ in combination with docetaxel (D) to $25 \%$ of the patients $(n=413) .17 \%$ of the patients $(n=279)$ received $\mathrm{A}+\mathrm{C}$ in combination with paclitaxel $(\mathrm{P}), 11 \% \mathrm{~A}+\mathrm{C}$ in combination with docetaxel $(n=178)$. Less frequently used were the taxane-based regimens $\mathrm{C}+\mathrm{D}$ and carboplatin $+\mathrm{D}$ (5 and $4 \%$, respectively) and the anthracycline based, taxane-free regimen $\mathrm{A}+\mathrm{C}(4 \%)$. Over time, a shift from the fluorouracil- and anthracycline-based regimen $\mathrm{F}+\mathrm{A}+\mathrm{C} \pm \mathrm{D}$ to anthracycline and taxane combinations $(\mathrm{A}+\mathrm{C}+\mathrm{D}$ and $\mathrm{A}+\mathrm{C}+\mathrm{P}$ ) can be observed for all patients, as well as within the subgroups with HR-positive/HER2-negative, HER2positive and triple negative tumours (Fig. 2b-d). For $81 \%$ of the patients with HER2-positive tumours, an additional trastuzumab therapy was documented (corresponding to $89 \%$ of the premenopausal and $80 \%$ of the postmenopausal patients, respectively). $82 \%$ of the premenopausal and $81 \%$ of postmenopausal patients with HR-positive tumours received endocrine therapy after cytotoxic (and possible HER2-targeted) therapy.

\section{Chemotherapy with and without taxanes}

Looking at all patients and all chemotherapy treatments (including those not shown in Table 1), 32\% of the patients $(n=528)$ received anthracycline-based chemotherapy 
Table 1 Patient characteristics at time of enrolment, split up according to the most common chemotherapy regimen

\begin{tabular}{|c|c|c|c|c|c|c|c|c|c|c|}
\hline \multirow{2}{*}{ Age at start of therapy $(n)^{*}$} & \multicolumn{2}{|c|}{$\mathrm{F}+\mathrm{A}+\mathrm{C}(n=456)$} & \multicolumn{2}{|c|}{$\begin{array}{l}\mathrm{F}+\mathrm{A}+\mathrm{C}+\mathrm{D} \\
(n=413)\end{array}$} & \multicolumn{2}{|c|}{$\mathrm{A}+\mathrm{C}+\mathrm{P}(n=279)$} & \multicolumn{2}{|c|}{$\mathrm{A}+\mathrm{C}+\mathrm{D}(n=178)$} & \multicolumn{2}{|c|}{$\begin{array}{l}\text { All patients } \\
(N=1650)\end{array}$} \\
\hline & \multicolumn{2}{|l|}{456} & \multicolumn{2}{|l|}{413} & \multicolumn{2}{|l|}{278} & \multicolumn{2}{|l|}{178} & \multicolumn{2}{|l|}{1649} \\
\hline Median (years) & \multicolumn{2}{|l|}{56.0} & \multicolumn{2}{|c|}{56.6} & \multicolumn{2}{|l|}{56.7} & \multicolumn{2}{|l|}{53.3} & \multicolumn{2}{|l|}{56.7} \\
\hline $\operatorname{BMI}(n)^{*}$ & \multicolumn{2}{|l|}{453} & \multicolumn{2}{|l|}{404} & \multicolumn{2}{|l|}{275} & \multicolumn{2}{|l|}{176} & \multicolumn{2}{|l|}{1626} \\
\hline \multirow{2}{*}{ Mean $\left(\mathrm{kg} / \mathrm{m}^{2}\right) \pm \operatorname{SD}\left(\mathrm{kg} / \mathrm{m}^{2}\right)$} & \multicolumn{2}{|c|}{$26.8 \pm 5.3$} & \multicolumn{2}{|c|}{$26.8 \pm 5.3$} & \multicolumn{2}{|c|}{$26.5 \pm 5.2$} & \multicolumn{2}{|c|}{$26.4 \pm 4.9$} & \multicolumn{2}{|c|}{$26.8 \pm 5.2$} \\
\hline & $n$ & $\%$ & $n$ & $\%$ & $n$ & $\%$ & $n$ & $\%$ & $n$ & $\%$ \\
\hline Any comorbidity ${ }^{\mathrm{a}}$ & 235 & 51.5 & 192 & 46.5 & 153 & 54.8 & 91 & 51.1 & 876 & 53.1 \\
\hline $\mathrm{CCI}=0$ & 394 & 86.4 & 376 & 91.0 & 245 & 87.8 & 165 & 92.7 & 1443 & 87.5 \\
\hline $\mathrm{CCI}=1$ & 29 & 6.4 & 13 & 3.1 & 15 & 5.4 & 4 & 2.2 & 71 & 4.3 \\
\hline $\mathrm{CCI} \geq 2$ & 33 & 7.2 & 24 & 5.8 & 19 & 6.8 & 9 & 5 & 136 & 8.2 \\
\hline Hypertension & 132 & 28.9 & 101 & 24.5 & 79 & 28.3 & 34 & 19.1 & 458 & 27.8 \\
\hline Diabetes mellitus & 35 & 7.7 & 24 & 5.8 & 21 & 7.5 & 9 & 5.1 & 128 & 7.8 \\
\hline Cardiovascular disorders & 6 & 1.3 & 3 & 0.7 & 5 & 1.8 & 1 & 0.6 & 39 & 2.4 \\
\hline Tumour subtype $(n)^{\mathrm{a}}$ & 442 & & 403 & & 275 & & 175 & & 1611 & \\
\hline HR-positive/HER2-negative & 301 & 68.1 & 254 & 63.0 & 165 & 60.0 & 104 & 59.4 & 949 & 58.9 \\
\hline HER2-positive & 83 & 18.8 & 87 & 21.6 & 61 & 22.2 & 29 & 16.6 & 402 & 25.0 \\
\hline Triple negative & 58 & 13.1 & 62 & 15.4 & 49 & 17.8 & 42 & 24.0 & 260 & 16.1 \\
\hline Tumour stage $e^{a, b}$ & 403 & & 364 & & 248 & & 162 & & 1456 & \\
\hline $\mathrm{I}$ & 197 & 48.9 & 59 & 16.2 & 33 & 13.3 & 31 & 19.1 & 407 & 28.0 \\
\hline II & 194 & 48.1 & 245 & 67.3 & 115 & 46.4 & 80 & 49.4 & 763 & 52.4 \\
\hline III & 12 & 3.0 & 60 & 16.5 & 100 & 40.3 & 51 & 31.5 & 286 & 19.6 \\
\hline Nodal stage ${ }^{\mathrm{a}}$ & 456 & & 413 & & 279 & & 178 & & 1650 & \\
\hline $\mathrm{N}-$ & 376 & 82.5 & 119 & 28.8 & 81 & 29.0 & 58 & 32.6 & 781 & 47.3 \\
\hline $\mathrm{N}+$ & 77 & 16.9 & 291 & 70.5 & 195 & 69.9 & 117 & 65.7 & 853 & 51.7 \\
\hline $\mathrm{NX}$ & 3 & 0.7 & 3 & 0.7 & 3 & 1.1 & 3 & 1.7 & 16 & 1.0 \\
\hline Local therapy ${ }^{\mathrm{a}}$ & 456 & & 413 & & 279 & & 178 & & 1650 & \\
\hline $\mathrm{BCS}$ & 362 & 79.4 & 296 & 71.7 & 173 & 62.0 & 120 & 67.4 & 1166 & 70.7 \\
\hline Post-BCS radiotherapy ${ }^{\mathrm{c}}$ & 322 & 89.0 & 258 & 87.2 & 138 & 79.8 & 109 & 90.8 & 1001 & 85.8 \\
\hline Mastectomy & 87 & 19.1 & 105 & 25.4 & 92 & 33.0 & 50 & 28.1 & 435 & 26.4 \\
\hline Post-mastectomy radiotherapy ${ }^{\mathrm{d}}$ & 28 & 32.2 & 74 & 70.5 & 65 & 70.7 & 33 & 66.0 & 259 & 59.5 \\
\hline Surgery unknown & 7 & 1.5 & 12 & 2.9 & 14 & 5.0 & 8 & 4.5 & 49 & 3.0 \\
\hline
\end{tabular}

Only the four mainly used regimens are shown; each regimen could be administered with or without additional HER2-inhibitor trastuzumab and/ or additional endocrine therapy

$A$ epirubicin or doxorubicin, $B C S$ breast conserving surgery, $B M I$ body mass index, $C$ cyclophosphamide, $C C I$ Charlson comorbidity index, $D$ docetaxel, Car carboplatin, $F$ fluorouracil, $P$ paclitaxel, $S D$ standard deviation

${ }^{a}$ Number of patients with data available on the respective parameter at time of enrolment

${ }^{\mathrm{b}}$ Tumour stage according to American Joint Committee on Cancer. 7th ed. New York, NY: Springer; 2010

${ }^{\mathrm{c}}$ Percentages refer to all patients who received BCS

${ }^{\mathrm{d}}$ Percentages refer to all patients who received mastectomy

without a taxane, $10 \%(n=163)$ received taxane-based chemotherapy without an anthracycline, and $57 \%(n=938)$ received an anthracycline/taxane-combination, with an increase over time from $46 \%$ in $2007-2008$ to $75 \%$ in 2013-2014 (Fig. 3a). Only 1\% of the patients $(n=21)$ received chemotherapy without anthracyclines or taxanes. The constant increase of patients treated with taxane-based regimen within all subgroups is displayed in Fig. 3. However, when stratified by nodal stage, this increase seems to be a result of the rising proportion of node-negative patients receiving taxanes (from $21 \%$ in 2007-2008 to $80 \%$ in 2013-2014, Fig. 3a), while in node-positive patients the use of taxane-based regimens was already very common at the start of the observation period, with a slight further increase (77\% in 2007-2008 and 88\% in 2013-2014, Fig. 3a). This pattern is present within all subgroups analysed (Fig. 3b-d). The largest increase could be observed for node-negative patients with HR-positive/HER2-negative 


\section{a All tumours}

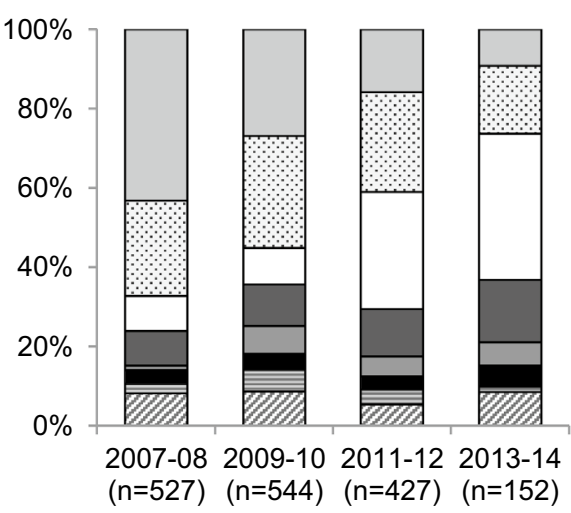

C HER2-positive tumours

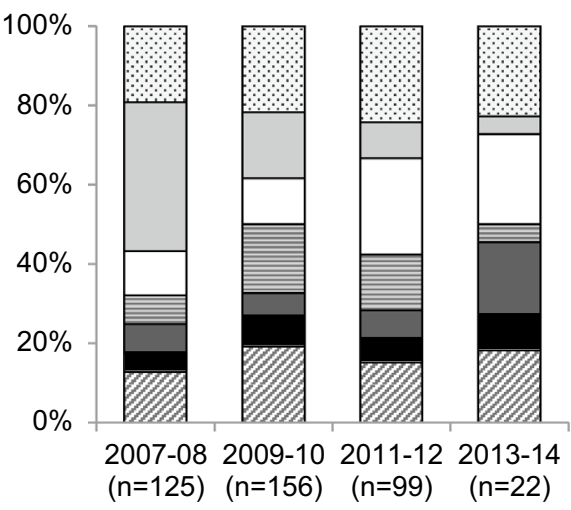

\section{b HR-positive/HER2-negative tumours}

$\square \mathrm{F}+\mathrm{A}+\mathrm{C}$ $\square \mathrm{F}+\mathrm{A}+\mathrm{C}+\mathrm{D}$ $\square \mathrm{A}+\mathrm{C}+\mathrm{P}$ $\square A+C+D$ $\square C+D$ $\mathrm{A}+\mathrm{C}$ $\forall \mathrm{Car}+\mathrm{D}$ øother

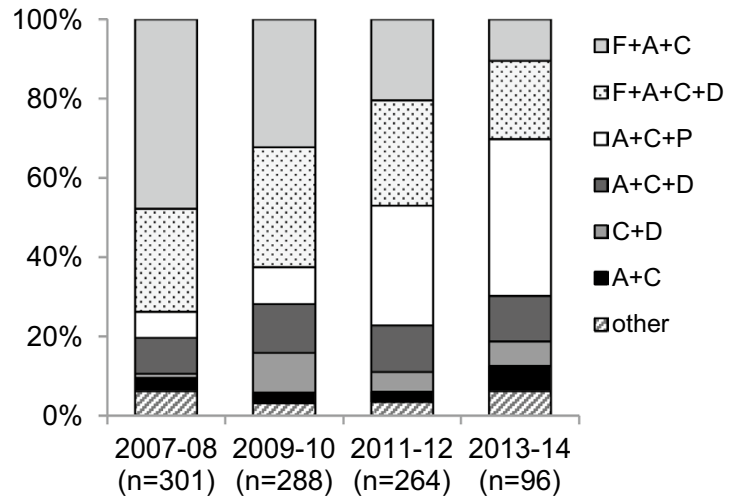

d Triple negative tumours $B F+A+C+D$ $\square \mathrm{F}+\mathrm{A}+\mathrm{C}$ $\square \mathrm{A}+\mathrm{C}+\mathrm{P}$ $\because \mathrm{Car}+\mathrm{D}$ $\square \mathrm{A}+\mathrm{C}+\mathrm{D}$ $\mathrm{A}+\mathrm{C}$ gother

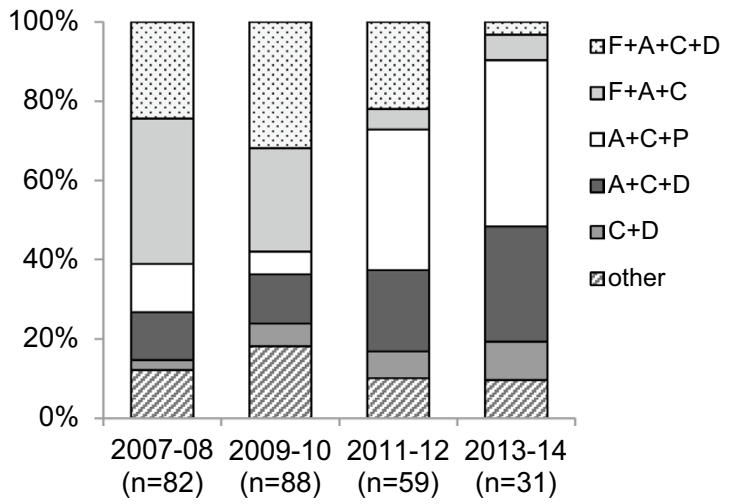

tive tumours. Each regimen could be administered with or without additional HER2-inhibitor and followed by additional endocrine therapy. $A$ epirubicin or doxorubicin, $C$ cyclophosphamide, $D$ docetaxel, Car carboplatin, $F$ fluorouracil, $P$ paclitaxel

\section{Discussion}

The aim of this analysis was to describe the different adjuvant cytotoxic treatment approaches for patients with early breast cancer in daily routine practice in Germany as well as to identify changes in treatment strategies since 2007 . The strengths of our study are the use of prospectively collected clinical data on systemic therapy in unselected primary breast cancer patients throughout Germany. The TMK is not limited to patients treated with a particular substance, thus providing a unique assessment of the different systemic treatment strategies applied outside of clinical trials, reflecting the "real-world" setting. Furthermore, we show a comprehensive analysis of treatment patterns of the breast cancer subtypes. Outcome data from the TMK will be analysed after an adequate follow-up time is reached, addressing the key question as to how the clinical efficacy shown in RCTs translates into clinical effectiveness in daily routine practice.

Our data show a shift from F + A-based to anthracycline/taxane-based regimens as preferred adjuvant treatment. than 2007. 


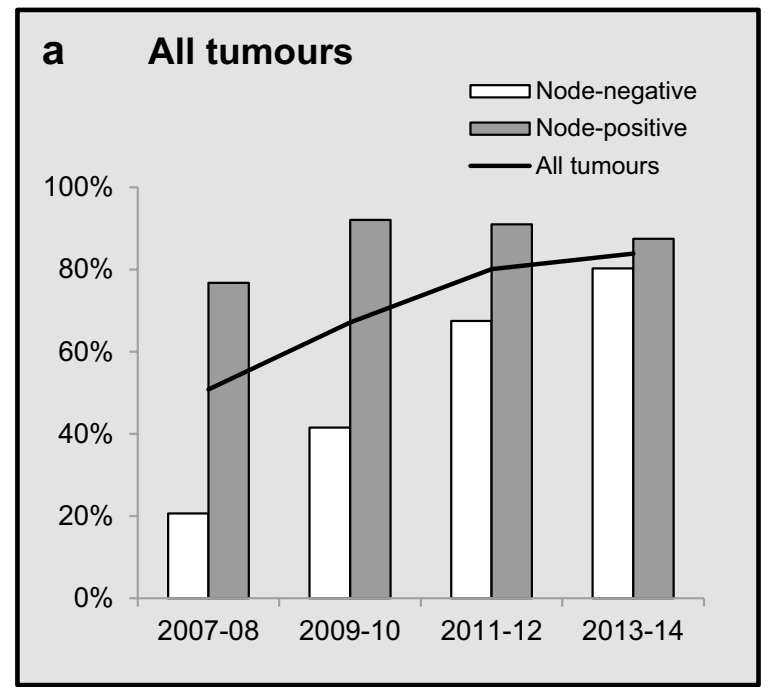

C HER2-positive tumours

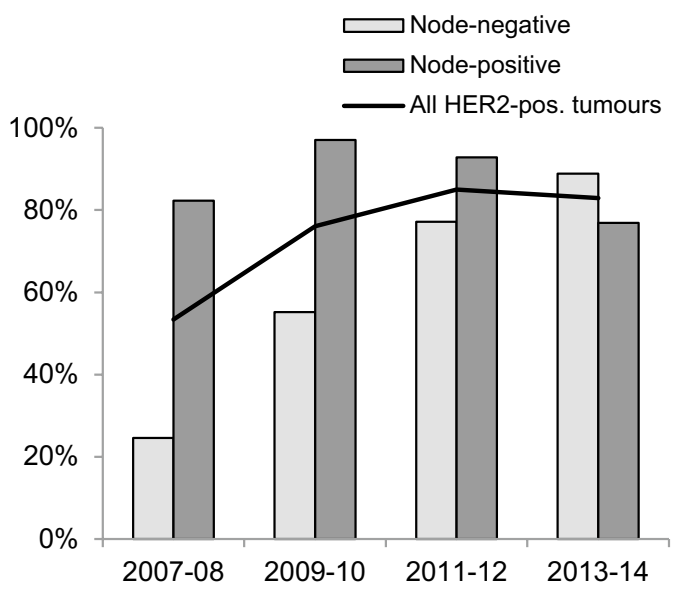

\section{b HR-positive/HER2-negative tumours

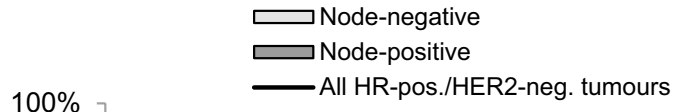

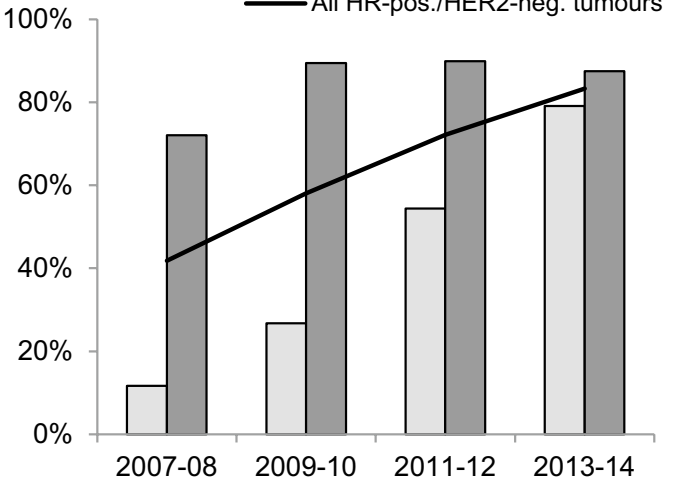

\section{d Triple negative tumours}

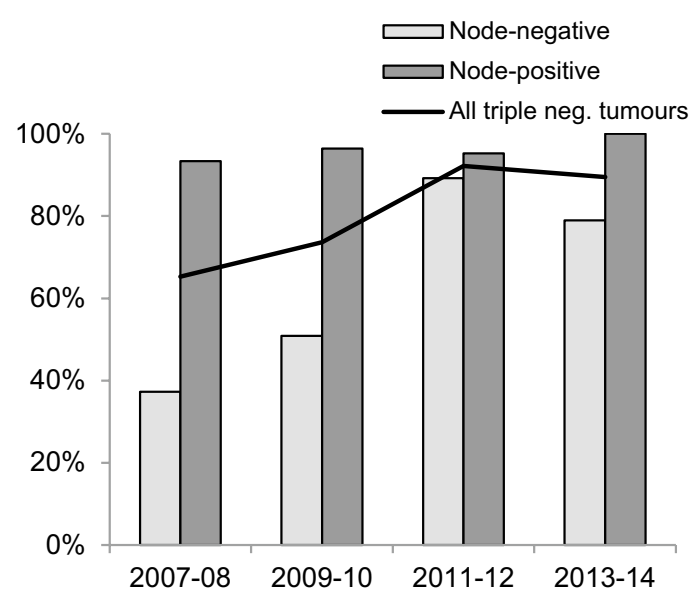

Fig. 3 Frequency of taxane-use over time. a All patients as well as split up according to the subgroups, b HR-positive/HER2-negative, c HER2positive and $\mathbf{d}$ triple negative. The line depicts the average for each group over time. pos. positive, neg. negative

While the increase of taxane use was apparent in all patient subgroups, the greatest increase was among node-negative patients. Our regression model examined the association of patient and tumour characteristics with receipt of taxane-free adjuvant chemotherapy. Positive nodal stage, triple negative or HER2-positive tumours, tumour grading, year of therapy and tumour size were significantly associated with decreasing odds for taxane-free therapy. Older age was the only factor associated with increasing odds for taxane-free therapy.

In our cohort study, $81 \%$ of the patients with HR-positive tumours were treated with endocrine therapy and additional HER2-inhibitors were documented for $81 \%$ of the patients with HER2-positive tumours. Our cohort did not include patients treated exclusively with endocrine therapy. In addition, although HR- and HER2-status were documented for $98 \%$ of our patients, we cannot distinguish between luminal
A and luminal B subtypes because data on Ki-67 status were not collected prior to 2011. Both limitations have to be taken into account when comparing our data with other published studies.

Compared to the patients from different European and Californian registry cohorts, our patients are similar with regard to the proportion of HR- and HER2-receptor subtypes [14-17], as well as distribution of age and CCI [17-20], if known restrictions of these registries (e.g. an age limit of 75) and our primary focus on patients receiving cytotoxic treatment are accounted for. The proportion of patients with CCI $\geq 1(12 \%)$ is also similar to patients in other reallife settings [17-19]. When compared to patients in RCTs, those treated in routine care are considerably different with regard to demographic and clinical characteristics [21]. In our TMK cohort, median age at start of adjuvant systemic 
Table 2 Multivariate analysis for the odds of chemotherapy with taxanes

\begin{tabular}{lccc}
\hline Parameter & \multicolumn{3}{c}{ Multivariate analysis } \\
\cline { 2 - 4 } & OR $95 \%$ CI & $p$ value \\
\hline Age at start of therapy (10 years) & 0.84 & $0.75-0.95$ & $0.0039^{* *}$ \\
Tumour subtype & & & \\
HER2-pos. vs. HR-pos./HER2- & 2.29 & $1.66-3.15$ & $<0.0001^{* * * *}$ \\
$\quad$ neg. & & & \\
Triple neg. vs. HR-pos./HER2- & 3.03 & $2.04-4.51$ & $<0.0001^{* * * *}$ \\
$\quad$ neg. & & & \\
Tumour size & & & \\
> T1 vs. T1 & 1.42 & $1.10-1.84$ & $0.0073^{* *}$ \\
Tis vs. T1 & 2.97 & $0.91-9.62$ & 0.0703 \\
TX vs. T1 & 4.40 & $0.28-68.03$ & 0.2894 \\
Nodal stage & & & \\
N+ vs. N- & 15.0 & $11.02-20.41$ & $<0.0001^{* * * *}$ \\
NX vs. N- & 2.34 & $0.71-7.73$ & 0.1650 \\
Tumour grading & & & \\
G2 vs. G1 & 1.92 & $1.12-3.29$ & $0.0171^{*}$ \\
G3 vs. G1 & 2.71 & $1.55-4.75$ & $0.0005^{* * *}$ \\
GX vs. G1 & 3.65 & $0.89-14.98$ & 0.0718 \\
Start of treatment (years) & 1.56 & $1.45-1.68$ & $<0.0001^{* * *}$ \\
\hline
\end{tabular}

Intercept OR 0.11, CI 0.05-0.26, $p$ value $<0.0001$

40 patients were excluded from this analysis due to missing covariates. CCI and the institution deciding on adjuvant therapy were not included in the final model

$C I$ confidence interval, $n e g$. negative, $O R$ odds ratio, pos. positive

$* p<0.05, * * p<0.01, * * * p<0.001$

${ }^{a}$ According to American Joint Committee on Cancer, 7th edn. New York, NY: Springer; 2010

treatment is 56 years, compared to approximately 50 years in RCTs [22-24]. Furthermore, the TMK includes patients who would have been excluded from RCTs because of the severity of comorbidities [22-24]. This indicates that the general state of health of our patients is less favourable, compared to patients in prospective clinical trials.

Positive nodal stage is a known predictor of relapse [25, 26] and pivotal studies [27, 28] and meta-analyses [29, 30] have shown a survival benefit of about 3\% (5-year survivalrate) by adding a taxane to an anthracycline-based chemotherapy for node-positive patients. Therefore, as expected, the highest rate of combined anthracycline/taxane regimen in our cohort is seen in the node-positive patient population. Nevertheless, the highest increase in taxane therapy can be seen in node-negative patients across all subtypes. The increase in taxane-based chemotherapy since 2008 over all patient subgroups in our cohort reflects changes in the treatment guidelines: while taxanes were not recommended for node-negative patients in 2008-2009, the use of taxanes for all patients receiving chemotherapy has been highly recommended since 2012 by the German AGO-guidelines [31].
However, the benefit of taxane-based chemotherapy for all node-negative patients has yet to be proven. Trials including node-negative patients that showed a survival benefit, either only included high risk patients [23] or showed only a significant benefit for the node-positive subgroup [25]. Nodenegative high-risk patients are probably the reason why the EBCTCG meta analysis in 2012 [32] also reported a small but significant reduction of the relative recurrence risk. This means, that some node-negative patients might benefit from taxane-based therapies, especially if other risk factors are present [23]. However, there is also evidence that as many as $70 \%$ of node-negative patients could be treated effectively with surgery, radiotherapy and endocrine therapy alone [33, 34]. On the other hand, due to the cardiotoxic side effects of anthracyclines, adjuvant combinations of docetaxel and cyclophosphamide (TC) are recommended for node-negative or low-risk node-positive breast cancer as an alternative to anthracycline-based therapies [35]. Nevertheless, only $10 \%$ of the patients of our cohort received anthracycline-free regimens.

Currently it is not possible to reliably identify node-negative patients, who will benefit from anthracycline/taxanecombination therapies. This is probably the main reason why an increasing proportion of node-negative patients in the TMK received such a combination therapy. However, if the overall risk of recurrence is small, the treatment choice has to be counterbalanced with treatment-related acute and long-term toxicities [36-38]. Especially in the light of recent findings regarding treatment choice based on gene-expression profiles, the decision for adjuvant chemotherapy treatment should not be taken lightly: the PlanB trial showed that patients with early HR-positive breast cancer and enhanced risk (assessed by the 21-gene recurrence score) had excellent 3-year survival rates despite omitted chemotherapy [39]. Similarly, 5-year survival rates of patients with high clinical, yet low genomic risk (assessed with the 70-gene signature test), were comparable regardless of the receipt of chemotherapy [40]. On the other hand, it has been shown that the patients' perceived estimation of increased risk of relapse is a major determinant for using adjuvant chemotherapy despite uncertainties regarding the degree of benefit when added to endocrine therapy in the low-risk HR-positive population. Thus the rise of taxane-use in node-negative patients in the TMK might also be partially attributed to patients' personal preference.

\section{Conclusion}

In summary, we show that adjuvant treatment with anthracycline/taxane-based chemotherapy has continuously increased in Germany since 2007; with the highest increase seen in the group of node-negative patients. Data from cohort studies 
like the TMK provide substantial information about the treatment of patients outside of clinical trials, which will help to gain more insight into benefit of changes in treatment strategies and the outcome of patients in routine practice.

Acknowledgements The authors thank all patients, physicians and study teams participating in the TMK. We thank Dr. Iris Benz-Rüd (iOMEDICO) for support and comments during design and set-up of the project and Dr. Leonora Houet (iOMEDICO) for critical comments on the manuscript. The authors thank Annette Fleitz (iOMEDICO) and Dr. Stephanie Dille (iOMEDICO) for preparation of the manuscript. The TMK is designed, managed and analysed by iOMEDICO and has received continuous financial support from Roche Pharma AG and temporary financial support from Hexal AG and Novartis Pharma $\mathrm{GmbH}$. None of the funders had any role in study design, data collection and analysis, interpretation of results, decision to publish, or preparation of the manuscript. The TMK Study Group collaborates with the Arbeitskreis Klinische Studien in onkologischen und hämatologischen Praxen e.V. and the Arbeitsgemeinschaft Internistische Onkologie in der deutschen Krebsgesellschaft e.V.

\section{Compliance with ethical standards}

Conflict of interest SD, CCS, DM, HT, LK, MF and MJ declare no conflict of interest concerning the topic of this publication. NM has received travel expenses from Roche, Novartis, Celgene and Amgen for attendance of advisory boards.

Open Access This article is distributed under the terms of the Creative Commons Attribution 4.0 International License (http://creativecommons.org/licenses/by/4.0/), which permits unrestricted use, distribution, and reproduction in any medium, provided you give appropriate credit to the original author(s) and the source, provide a link to the Creative Commons license, and indicate if changes were made.

\section{References}

1. Robert Koch-Institut, Gesellschaft der epidemiologischen Krebsregister in Deutschland e.V., editors. Krebs in Deutschland 2009/2010. 9. Ausgabe. Berlin: Robert Koch-Institut und die Gesellschaft der epidemiolgischen Krebsregister in Deutschland e.V.; 2013.

2. Holleczek B, Arndt V, Stegmaier C, Brenner H. Trends in breast cancer survival in Germany from 1976 to 2008-a period analysis by age and stage. Cancer Epidemiol. 2011;35:399-406.

3. Berry DA, Cronin KA, Plevritis SK, Fryback DG, Clarke L, Zelen $\mathrm{M}$, et al. Effect of screening and adjuvant therapy on mortality from breast cancer. N Engl J Med. 2005;353:1784-92.

4. Goldhirsch A, Wood WC, Coates AS, Gelber RD, Thurlimann B, Senn H-J, et al. Strategies for subtypes-dealing with the diversity of breast cancer: highlights of the St Gallen International Expert Consensus on the Primary Therapy of Early Breast Cancer 2011. Ann Oncol. 2011;22:1736-47.

5. Wirapati P, Sotiriou C, Kunkel S, Farmer P, Pradervand S, HaibeKains B, et al. Meta-analysis of gene-expression profiles in breast cancer: toward a unified understanding of breast cancer sub-typing and prognosis signatures. Breast Cancer Res. 2008;10:R65.

6. Coates AS, Winer EP, Goldhirsch A, Gelber RD, Gnant M, Piccart-Gebhart M, et al. Tailoring therapies-improving the management of early breast cancer: St Gallen International Expert
Consensus on the Primary Therapy of Early Breast Cancer 2015. Ann Oncol. 2015;26:1533-46.

7. Jackisch C, Untch M, Chatsiproios D, Lamparter C, Overkamp $\mathrm{F}$, Lichtenegger $\mathrm{W}$, et al. Adherence to treatment guidelines in breast cancer care-a retrospective analysis of the 'Organgruppe Mamma der Arbeitsgemeinschaft Gynaekologische Onkologie'. Breast Care. 2008;3:87-92.

8. Inwald EC, Ortmann O, Zeman F, Koller M, Hofstädter F, Gerstenhauer M, et al. Guideline concordant therapy prolongs survival in HER2-positive breast cancer patients: results from a large population-based cohort of a cancer registry. Biomed Res Int. 2014;2014:1-10.

9. Engel J, Nagel G, Breuer E, Meisner C, Albert U-S, Strelocke K, et al. Primary breast cancer therapy in six regions of Germany. Eur J Cancer. 2002;38:578-85.

10. Wöckel A, Kurzeder C, Geyer V, Novasphenny I, Wolters R, Wischnewsky M, et al. Effects of guideline adherence in primary breast cancer-a 5-year multi-center cohort study of 3976 patients. Breast. 2010;19:120-7.

11. Early Breast Cancer Trialists' Collaborative Group (EBCTCG). Comparisons between different polychemotherapy regimens for early breast cancer: meta-analyses of long-term outcome among 100000 women in 123 randomised trials. Lancet. 2012;379:432-44.

12. Fietz T, Tesch H, Rauh J, Boller E, Kruggel L, Jänicke M, et al. Palliative systemic therapy and overall survival of 1,395 patients with advanced breast cancer-results from the prospective German TMK cohort study. Breast. 2017;34:122-30.

13. Quan H, Li B, Couris CM, Fushimi K, Graham P, Hider P, et al. Updating and validating the Charlson comorbidity index and score for risk adjustment in hospital discharge abstracts using data from 6 countries. Am J Epidemiol. 2011;173:676-82.

14. Minicozzi P, Bella F, Toss A, Giacomin A, Fusco M, Zarcone $\mathrm{M}$, et al. Relative and disease-free survival for breast cancer in relation to subtype: a population-based study. J Cancer Res Clin Oncol. 2013;139:1569-77.

15. Schrodi S, Tillack A, Niedostatek A, Werner C, SchubertFritschle G, Engel J. No survival benefit for patients with treatment in certified breast centers-a population-based evaluation of German cancer registry data. Breast J. 2015;21:490-500.

16. Tumorregister München. Spezielle Auswertungen C50: Mammakarzinom (Frauen) Krankheitsbild [Internet]. Tumorregister München; 2015. https://www.tumorregister-muenchen.de/facts/ spec/spec_C50f_02_20170330_krank.pdf. Accessed 18 Nov 2015.

17. Kurian AW, Lichtensztajn DY, Keegan THM, Leung RW, Shema SJ, Hershman DL, et al. Patterns and predictors of breast cancer chemotherapy use in Kaiser Permanente Northern California, 2004-2007. Breast Cancer Res Treat. 2013;137:247-60.

18. Land LH, Dalton SO, Jensen M-B, Ewertz M. Influence of comorbidity on the effect of adjuvant treatment and age in patients with early-stage breast cancer. $\mathrm{Br} \mathrm{J}$ Cancer. 2012;107:1901-7.

19. Berglund A, Wigertz A, Adolfsson J, Ahlgren J, Fornander T, Wärnberg F, et al. Impact of comorbidity on management and mortality in women diagnosed with breast cancer. Breast Cancer Res Treat. 2012;135:281-9.

20. Joerger M, Thürlimann B, Savidan A, Frick H, Bouchardy C, Konzelmann I, et al. A population-based study on the implementation of treatment recommendations for chemotherapy in early breast cancer. Clin Breast Cancer. 2012;12:102-9.

21. Treweek S, Dryden R, McCowan C, Harrow A, Thompson AM. Do participants in adjuvant breast cancer trials reflect the breast cancer patient population? Eur J Cancer. 2015;51:907-14.

22. Ellis P, Barrett-Lee P, Johnson L, Cameron D, Wardley A, O'Reilly $\mathrm{S}$, et al. Sequential docetaxel as adjuvant chemotherapy 
for early breast cancer (TACT): an open-label, phase III, randomised controlled trial. Lancet. 2009;373:1681-92.

23. Martín M, Seguí MA, Antón A, Ruiz A, Ramos M, Adrover E, et al. Adjuvant docetaxel for high-risk, node-negative breast cancer. N Engl J Med. 2010;363:2200-10.

24. Sparano JA, Wang M, Martino S, Jones V, Perez EA, Saphner T, et al. Weekly paclitaxel in the adjuvant treatment of breast cancer. N Engl J Med. 2008;358:1663-71.

25. Harbeck N, Thomssen C. A new look at node-negative breast cancer. Oncologist. 2011;16:51-60.

26. Kümmel A, Kümmel S, Barinoff J, Heitz F, Holtschmidt J, Weikel $\mathrm{W}$, et al. Prognostic factors for local, loco-regional and systemic recurrence in early-stage breast cancer. Geburtshilfe Frauenheilkd. 2015;75:710-8.

27. Martin M, Pienkowski T, Mackey J, Pawlicki M, Guastalla J-P, Weaver C, et al. Adjuvant docetaxel for node-positive breast cancer. N Engl J Med. 2005;352:2302-13.

28. Henderson IC, Berry DA, Demetri GD, Cirrincione CT, Goldstein $\mathrm{LJ}$, Martino S, et al. Improved outcomes from adding sequential paclitaxel but not from escalating doxorubicin dose in an adjuvant chemotherapy regimen for patients with node-positive primary breast cancer. J Clin Oncol. 2003;21:976-83.

29. Ferguson T, Wilcken N, Vagg R, Ghersi D, Nowak AK. Taxanes for adjuvant treatment of early breast cancer. Cochrane Database Syst Rev. 2007;4:CD004421.

30. De Laurentiis M, Cancello G, D'Agostino D, Giuliano M, Giordano A, Montagna E, et al. Taxane-based combinations as adjuvant chemotherapy of early breast cancer: a meta-analysis of randomized trials. J Clin Oncol. 2008;26:44-53.

31. Arbeitsgemeinschaft Gynäkologische, Onkologie e.V. (AGO). AGO-Online guidelines/recommendations [Internet]. http://www. ago-online.de/de/infothek-fuer-aerzte/leitlinienempfehlungen/ mamma/. Accessed 11 May 2017.

32. Early Breast Cancer Trialists' Collaborative Group (EBCTCG), Peto R, Davies C, Godwin J, Gray R, Pan HC, et al. Comparisons between different polychemotherapy regimens for early breast cancer: meta-analyses of long-term outcome among 100,000 women in 123 randomised trials. Lancet. 2012;379:432-44.

33. Harbeck N, Dettmar P, Thomssen C, Henselmann B, Kuhn W, Ulm $\mathrm{K}$, et al. Prognostic impact of tumor biological factors on survival in node-negative breast cancer. Anticancer Res. 1998;18:2187-97.

34. Babacan T, Buyukhatipoglu H, Balakan O, Kertmen N, Suner A, Sarici $\mathrm{F}$, et al. Chemotherapy might not be beneficial in lymph node-negative, hormone-positive, and HER2-negative breast cancer patients: a long-term retrospective analysis. J BUON. 2015;20:479-86.

35. Rampurwala MM, Rocque GB, Burkard ME. Update on adjuvant chemotherapy for early breast cancer. Breast Cancer (Auckl). 2014;8:125-33.

36. Eckhoff L, Knoop A, Jensen MB, Ewertz M. Persistence of docetaxel-induced neuropathy and impact on quality of life among breast cancer survivors. Eur J Cancer. 2015;51:292-300.

37. Andersen KG, Jensen M-B, Kehlet H, Gärtner R, Eckhoff L, Kroman N. Persistent pain, sensory disturbances and functional impairment after adjuvant chemotherapy for breast cancer: cyclophosphamide, epirubicin and fluorouracil compared with docetaxel + epirubicin and cyclophosphamide. Acta Oncol. 2012;51:1036-44.

38. Azim HA, de Azambuja E, Colozza M, Bines J, Piccart MJ. Longterm toxic effects of adjuvant chemotherapy in breast cancer. Ann Oncol. 2011;22:1939-47.

39. Gluz O, Nitz UA, Christgen M, Kates RE, Shak S, Clemens M, et al. West German Study Group Phase III PlanB Trial: first prospective outcome data for the 21-gene recurrence score assay and concordance of prognostic markers by central and local pathology assessment. J Clin Oncol. 2016;34:2341-9.

40. Cardoso F, van't Veer LJ, Bogaerts J, Slaets L, Viale G, Delaloge $\mathrm{S}$, et al. 70-gene signature as an aid to treatment decisions in earlystage breast cancer. N Engl J Med. 2016;375:717-29.

\section{Affiliations}

\section{Steffen Dörfel ${ }^{1}$. Claus-Christoph Steffens ${ }^{2} \cdot$ Dirk Meyer $^{3} \cdot$ Hans Tesch $^{4} \cdot$ Lisa Kruggel $^{5} \cdot$ Melanie Frank $^{6}$. Martina Jänicke ${ }^{5} \cdot$ Norbert Marschner ${ }^{7}$ (D) The TMK-Group (Tumour Registry Breast Cancer)}

Steffen Dörfel

doerfel@onkozentrum.de

Claus-Christoph Steffens

c.steffens@stadtteilklinik.de

Dirk Meyer

meyer.osp@gmx.de

Hans Tesch

hans.tesch@telemed.de

Lisa Kruggel

lisa.kruggel@iomedico.com

Melanie Frank

melanie.frank@iomedico.com

Martina Jänicke

martina.jaenicke@iomedico.com
1 OncoCentre Dresden/Freiberg, Leipziger Str. 118, 01127 Dresden, Germany

2 Centre for Haematology and Oncology, Harsefelder Str. 6-8, 21680 Stade, Germany

3 Centre for Oncology, Nikolausberger Weg 36, 37073 Göttingen, Germany

4 Centre for Haematology and Medical Oncology at Bethanien, Im Prüfling 17-19, 60389 Frankfurt/Main, Germany

5 Clinical Epidemiology and Health Economics, iOMEDICO, Hanferstr. 28, 79108 Freiburg, Germany

6 Statistics, iOMEDICO, Hanferstr. 28, 79108 Freiburg, Germany

7 Outpatient-Centre for Interdisciplinary Oncology and Haematology, Wirthstrasse 11c, 79110 Freiburg, Germany 